\title{
The Impact of the American English Learning upon Chinese College Students’ Ideology
}

\author{
Xiao Yue \\ Department of English, Zhongnan University of Economics and Law, Wuhan, China \\ Email: 934124590@qq.com
}

Received December 20 $0^{\text {th }}, 2011$; revised January 15 ${ }^{\text {th }}$, 2012; accepted January 31 ${ }^{\text {st }}, 2012$

\begin{abstract}
In recent decades, many researchers have devoted themselves to the study of the impact of American ideology upon Chinese college students. However, few of researches have been made in this area in view of language attrition. This thesis mainly analyses the transfer of Chinese college students' ideology caused by the language attrition during the process of American English learning, such as the regression of Chinese language in different degrees and the decline of self-identities in Chinese culture. The transfer of ideology is manifested in the aspects of Chinese college students' ideas, values, self-identities, etc. This thesis also provides evidence for the current situations that Chinese college students' ideology was transferred by the first language attrition. Language attrition is a method different from other traditional research methods, and it is a whole new point of view at a cultural level.
\end{abstract}

Keywords: Language Attrition; Ideology; English Learning

\section{Introduction}

The globalization of world economy has come into being since the World War II, emerging its primary form in the 80s of the 20th century, accelerating its development in the 90s, blooming at the beginning of the 21st century, and it strongly promotes the transmission of the Western ideology. In this thesis, the Western ideology particularly refers to the American ideology, because as a matter of fact, America has been the superpower since the World War II and the center of many areas, including politics, economy and culture. Therefore, American ideology plays a dominant or leading role in the Western ideology. In this sense, the transmission of Western ideology is basically the transmission of American ideology. Moreover, language is known as the most important carrier of culture, so the learning of American English would certainly influence the Chinese college students' ideology, especially considering the fact that the fever of American English Learning reached a climax during the first decade of the 21st century, and the value of mastering American English has risen to an unprecedented level in China nowadays. The degree of undergraduates' English standard has become a significant ruler in the selection process of their job hunting or further study.

Many researchers have devote their efforts into the study of the phenomenon described above; however, only a limited number of studies have been put into the newly emerging subfield of applied linguistics: Language attrition. Since in previous studies on first language attrition little attention has been paid to the in-between position of Chinese college students, their senses of belonging or not-belonging and their attempts (or not) to re-create their self in a second language -environment, my research deals with the issue: the link between the first language attrition and the transfer of ideology, concentrating in particular on Chinese college students. This thesis aims at analyzing the theory of Language attrition with reference to Chinese college students' psychological and philosophical phenomena, such as idea, belief, conception, psychology, cultural value and selfidentity.

\section{Literature Review}

\section{Definition of Language Attrition}

Language attrition is the loss of a first or second language or a portion of that language by individuals. Speakers who routinely use more than one language may not use either of their languages in ways which are exactly like that of a monolingual speaker. In sequential bilingualism, for example, there is often evidence of interference from the first language (L1) in the second language (L2) system or the other way around. Describing these interference phenomena and accounting for them on the basis of theoretical models of linguistic knowledge has long been a focus of interest of Applied Linguistics. More recently, research has started to investigate linguistic traffic which goes the other way: "The second language interferences and contact with the first language. Such phenomena are probably experienced to some extent by all bilinguals. They are, however, most evident among speakers for whom a language other than the L1 has started to play an important, if not dominant, role in everyday life” (Schmid \& Köpke, 2007).

\section{The Introduction and Development of Language Attrition}

\section{Academic Study Origins}

Only in the past few decades has the study of language attrition become a sub-field of linguistics beginning with a 1980 conference at the University of Pennsylvania titled "Loss of Language Skills" (Lambert and Freed, 1982). The aim of this conference was to discuss areas of second language attrition and the possible areas of future research in first language loss. The conference revealed that attrition is a wide topic covering different types of language loss and that there are many possible reasons for the 
loss. A related phenomenon is the loss of language due to contact with other, more dominant languages, possibly leading to language death.

This field gained new momentum with two conferences held in Amsterdam in 2002 and 2005, as well as a series of graduate workshops and panels at international conferences such as the International Symposium on Bilingualism held between 2007 and 2009, the annual conferences of the European Second Language Association and the AILA (Association Internationale de Linguistique Applique) World Congress in 2008. The outcomes of some of these meetings have been published in edited volumes (Schmid et al., 2004; Köpke et al., 2007) and special issues of journals, such as the Journal of Neurolinguistics, the International Journal of Bilingualism and Bilingualism: Language and Cognition.

\section{Development}

Language attrition research involves many fields, suck as psychology, neurology, sociology, linguistics and so on; the research targets also vary greatly, for examples, pathological and non pathological language attrition. Because of the differences of the researchers' start points, their focuses, purposes and the outcomes are different. The early researches on the definition of the language attrition lack consistency. Therefore various related terms emerged, such as language loss, language atrophy, language aphasia, etc in pathological researches; language change, language shift, language death, language obsolescence, etc in sociological researches; language forgetting, language regression, language erosion, language deterioration, language decay, language disintegration, language weakening, language mutation, etc in psycholinguistic researches. The language attrition in this thesis mainly refers to "Language Forgetting”, a theory put forward by Hansen in 2001. He explains the research achievement of the recent five years, including Savings Paradigm Hypothesis, Relearning Hypothesis. Schmid systematically appraises the language attrition research from the sociolinguistics. Hypothesis includes: Regression Hypothesis, Retrieval Failure Hypothesis, Savings Paradigm Hypothesis, Relearning Hypothesis, Interlanguage Hypothesis, Universal Grammar Hypothesis and other hypotheses (Yang Lianrui, 2009). This thesis mainly focuses on the regression hypothesis which means "last thing learned, first thing lost".

The regression hypothesis, first formulated by Roman Jakobson in 1941, can be traced back to the origin of psychology and psychoanalysis. In General, it states what was learned first will be remained last, both in "normal" processes of forgetting and in pathological conditions such as aphasia or dementia (Weltens, 1986). As a template for language forgetting, the regression hypothesis has long seemed to be an attractive paradigm. However, as Keijzer points out, "Regression is not in itself a theoretical or explanatory framework. Both order of acquisition and order of attrition need to be put into the larger context of linguistic theory in order to gain explanatory adequacy." However, there is also considerable interaction between the first and second language, so a straightforward "regression pattern" cannot be observed. Citing the studies on the regression hypothesis that have been done, Yukawa says that the results have been contradictory. It is possible that attrition is a situation depending on a number of variables such as age, proficiency, literacy, the similarities between the first language and the second language, and whether the first language or the second language is attriting.

\section{Background of American English Learning in China}

\section{Establishment of American English}

Isolationism turned out to be worked very well for America during the First World War. The old European colonial empires gradually fell apart and their power all over the world was greatly weakened by the wars. However, America escaped the First World War, saving its energy and money for developing while others suffering from the trauma left behind the war, and America gained its hegemony in the world after the Second World War and the Cold War. America was the super power of the world at that time, its influence spread in all areas, including economy, culture, education, military and politics, especially in culture. In order to do business with America, many old European countries who were proud of their own languages, like France, started to learn American English. Then America was the country who owned the best education and the best technology became the centre of the world in all respects. Therefore, to learn its language seems to be the only way to get access to the top of the world.

Now, American English is still the common language (a language spoken and understood by all or most of the world's population) of our global village. With the developing of the high-speed network, the interwoven communication of international economy and culture, American English continue to reinforce its dominating role. Statistics proves that over 60 countries use English as their lingua franca (a language systematically used to make communication possible between people not sharing a mother tongue, in particular when it is a third language, distinct from both mother tongues.) or official language (a language that is given a special legal status in a particular country, state, or other jurisdiction), which is nearly $25 \%$ of the total numbers of the countries or districts of the world. The number of people who can use English in different forms was approaching 1.6 billion, that's one third of the global population. Over $80 \%$ of the internet pages are written in English. Early in the $80 \mathrm{~s}$ of the $20^{\text {th }}$ century, three-quarters of the global mails, posts, faxes were written in English, and 50\% of the science and technology magazines were published in English. In internet technology, 80\% of the data was stored in English. In the United Nations, the world's largest organization, English has the highest usage. $80 \%$ of the original paper work is done in English, while only $20 \%$ is done in the other 5 languages: French, Chinese, Spanish, Russian, and Arabic (Zhu Weilie, 2002). The value of English is far more important than the other 6 thousand languages existing in the world today, and the culture attached to the wide-spreading English is significant.

\section{Importance of American English in China}

Since the founding of New China, more and more people have begun to learn foreign languages. After the restoration of the college entrance examination in 1977 and the "Reform and opening up” policy in 1978, English learning became the required subject in Chinese education. "At present, Chinese government is sparing no effort to promote foreign languages in English-based education, teaching and research, regarding English as an important link for the development of comprehensive education, an important aspect of improving the overall quality. English teaching in our country is an important aspect of modernization, a key to reformation and opening, one of the most important safeguards to bring about a great rejuvenation of the Chinese nation ultimately” (Lin Caidan, 2009). 
In China, American English teaching permeates to all levels of education, from primary students up to doctoral student. Now, even kindergartens provide American English programs. Parents who are afraid of their children to get behind other children are eager to send their children to study English as early as possible. English training classes like: New Oriental Education \& Technology Group, Crazy English, New Concept English, Follow Me, etc., have sprung up like mushrooms. CET 4 (College English Test Band 4) and CET 6 (College English Test Band 6) are the most important degree tests of Chinese college students' English proficiency. Also, like TEM 4 (Test for English Major-Degree 4), TEM 8 (Test for English Major-Degree 8), TOEFL (The Test of English as a Foreign Language), IELTS (International English Language Testing System) are designed for students to testify their ability to use English and give them certifications. An undergraduate Student will not graduate without passing CET 4. An English-majored student will not graduate without passing TEM 4. Most of the companies, institutions, organizations consider English ability as one of the primary qualities when they choose their employees. For Job applying, English plays a very important part in job analysis and job promoting. It is no exaggeration to say that to learn English well is the key to getting close to a bright future for a college student. Social environment greatly influence the learners' motivation. The theory of language socialization regards the study of language, culture and social behavior as a continuous blending process.

\section{Modern American Ideology}

\section{Definition of Ideology}

So far, it's hard to see any short adequate definition of ideology given by scholars. It's not because their intelligence is not qualified to have this job done, but the term "ideology" has a wide range of complex meanings. It is not a very wise idea to try to concentrate the whole rich meanings into one single comprehensive definition even if it is possible, because it would simply destroy the connotation of the word.

To indicate the variety of it's meaning, Terry Eagleton lists at random some definitions of ideology currently in circulation:

1) The process of production of meanings, signs and values in social life.

2) A body of ideas characteristic of a particular social group or class.

3) Ideas which help to legitimate a dominant political power.

4) False ideas which help to legitimate a dominant political power.

5) Systematically distorted communication.

6) That which offers a position for a subject.

7) Forms of thought motivated by social interests.

8) Identity thinking.

9) Socially necessary illusion.

10) The conjuncture of discourse and power.

11) The medium in which conscious social actors make sense of their word.

12) Action-oriented sets of beliefs.

13) The confusion of linguistic reality.

14) Semiotic closure.

15) The indispensable medium in which individuals live out their relations to a social structure.

16) The process whereby social life is converted to a natural reality.
The word "Ideology", one might say, is woven of a whole tissue of different conceptual strands; it is traced through by divergent histories, and it is probably more important to assess what is valuable or can be discarded in each of these lineages than to merge forcibly into some Grand Global Theory (Eagleton, 1991: p. 1).

The term ideology has a wide rang of historical meanings, all the way from the unworkably broad sense of the social determination of thought to the suspiciously narrow idea of the deployment of false ideas in the direct interests of a ruling class. Very often, it refers to the ways in which signs, meanings and values help to reproduce a dominant social power; but it can also denote any significant conjuncture between discourse and political interests (Eagleton, 1991: p. 221).

The term "ideology" consists of a set of ideas, such as purpose, thought, and expectation. It's a comprehensive vision, a system of abstract thoughts attached to public matters that can influence the society and the people inside the society. With its definition, it's easier to understand the American ideology better.

\section{American Ideology}

American Ideology is such an abstract and complicated term; this thesis would concentrate on some aspects of the American Ideology.

\section{Civil Society and Individualism}

America is a highly civilized society which consist of all kinds of institutions and groups that are mostly non-governmental organizations, such as academia, charities, sports clubs, trade unions, environmental groups, private voluntary organizations, men's groups, women's groups, religious organizations, etc. All of these are the foundation of a highly functioning society. "Fellowship is life, and lack of fellowship is death, but in hell there is no brotherhood but everyone for himself.” The leader of the Peasants' Revolt John Ball states these words. People, have different culture backgrounds but share the same interests, purpose and value, get together help the government to make the society better and warmer. Their contribution to the society is more like a supplement of the government. In America, the most important part of education is to teach students to offer voluntary help. Most of the American universities consider the experience of doing voluntary works as one of most important qualities of university students. A system in America has been already formed for students to do voluntary activities including taking care of the elder, cleaning the beaches, talking to the people in the addiction treatment centre, and helping the homeless people and so on. The purpose of the voluntary is to shorten the distance between people and creates a more harmony atmosphere of the society. To build up a civil society is also an access to the success of social democracy.

Individualism is a conception different from liberalism; it focuses on the quality of being an individual, more specific, the characteristic and style of life. Individualists pursue personal goals, desires, independence and self-reliance. There is always an external interference between one's own interests and society, family or any other group or institution. An individualist would seek for his or her own interest or at least demand the right to serve his or her own interests, without taking the interests of society into consideration. However an individualist is not the same as an egoist. The individualist does not lend cre- 
dence to any philosophy that requires the sacrifice of the selfinterest of the individual for any higher social causes.

\section{Equality and Natural Selection}

In the very beginning of opening of the United States Declaration of Independence, Thomas Jefferson states that: "We hold these truths to be self-evident, that all men are created equal, that they are endowed by their Creator with certain unalienable Rights, that among these are Life, Liberty, and the Pursuit of Happiness. That to secure these rights, Governments are instituted among Men, deriving their just powers from the consent of the governed.” Since the founding of America in 1776, this nation has been the biggest immigration country in the world. Nearly all kinds of people with different nationalities gathered in here: White people, Black people, and Yellow people; Spanish, Italian, Chinese, Japanese, Mexican, etc. However, difference doesn't cause much conflict and America is still a very strong country due to the idea equality. This idea is ensured by law and enhanced by man. Margie between people of different skin, from different countries it is now a very common thing. Women in America have won the right to vote since 1920, and now they're having more and more freedom and power than before. On the whole, America is still a country which demonstrates great equality.

On the other side of the picture, American is also greatly influenced by the theories of Darwinism, which became wide spread in the late nineteenth century. The core spirit of Darwinism is the "Social Darwinism" or the "Natural Selection". Social Darwinism is a contradictory term that raises the ideas of survival of the fittest. Social Darwinism commonly refers to the struggle for existence being between national or racial groups used to justify social policies, and the most observably part of such views emphasized competition between individuals in free market capitalism. In sociology it has been defined as a theory of social evolution which asserts that "There are underlying, and largely irresistible, forces acting in societies which are like the natural forces that operate in animal and plant communities. One can therefore formulate social laws similar to natural ones. These social forces are of such a kind as to produce evolutionary progress through the natural conflicts between social groups. The best-adapted and most successful social groups survive these conflicts, raising the evolutionary level of society generally, or in short, the survival of the fittest" (Nicholas Abercrombie, 2000: p. 51). Meritocracy is another form of the manifestation of Social Darwinism. Though meritocracy basically means a government's system wherein individual's ability or value was judged according to their "merits", or in general, intelligence, credentials and education, determined through examinations or other forms of evaluations, but the word itself still belongs to ideology. Critics believe that meritocracy potentially lacks in clarity and therefore open to misuse, because "merit" itself is a highly subjective term. The common phenomenon in American is that children born in upper class families get the best recourses of education; they go to private schools which have the highest reputations and, of course, pay the highest tuitions which the ordinary people couldn't afford even if they raise a loan. In private schools, children from upper class families learn from best teachers, use the best teaching facilities, and get more opportunities from Ivy League Schools (They are Brown, Columbia, Cornell, Yale, Harvard, Pennsylvania, Princeton, and Dartmouth). After graduation they enter the best companies, organizations, institutions and become the main dominator of the society following their forefather's footsteps. On the contrary, children from public schools are not so lucky. With out enough money, they will not receive better education, as a result they will end up with less advantaged universities, less advantaged jobs, and following the footsteps of their forefathers will become the employees of the children form upper class families and make money for them. Meritocracy may train talents for the society, but it will also cause a vicious spiral for the society, and that is the side effects of the natural selection.

Though Americans regard equality as a holy right of mankind, society is a complicated contradiction system, so it's necessary to view the picture from the all aspects. Human society is unlike any other society in the world, mankind needs tolerance and love. Only when a society cares the weak and pay attentions to the vulnerable groups, can we regard this society as a true human society.

Other aspects of American Ideology would be listed in the following part of the thesis.

\section{The Impact on Students' Ideology}

With the learning of American English, Chinese college students would somehow lose their mother language, Chinese, according to the theory of language attrition, and thus would lose their sense of belonging of Chinese culture and turn to the culture they are studying.

\section{Impact on Idea and Culture Value}

Sometimes, it is very confusing for Chinese students to understand the way Americans deal with things. As we all know America is a highly developed country and it is a well organized civil society. They are always ready to give their hands to the people that need help. However, the way they offer their help is very different from that of the Chinese. For example, in China, when we offer our help, we often say it in a more direct way, in America, they often say, "May I help you?” or “Can I offer you my help?” They could ask permission first and the subject of the sentence is "I". In this way, the one who receives help would not feel he or she is inferior to others. It's more polite and it's also reflects the idea of equality. For example, in China, a young man would be praised for giving his seat to an elder man on the bus. But in America, the same thing would turn out to be offending. Because if you give your seat to the elder without permission the elder may think you hold the idea that he is too old to take care of himself. So now, volunteers in Chinese colleges are more likely to say, "May I help you?" when they are trying to help someone. That is one way to show the changing their thinking patterns.

During the process of English learning, the famous speech Barack Obama made when he was elected the president of the United States is familiar to all college students, in his speech he stated, "If there is anyone out there who still doubts that America is a place where all things are possible; who still wonders if the dream of our founders is alive in our time; who still questions the power of our democracy, tonight is your answer.” The speech is such a powerful piece that no one would not be deeply affected. Now in Chinese colleges, no matter where you come from, rural areas or big cities, you have the equal chance to receive higher education. Chinese universities are offering more subsidy and new policies that aiming at the students who need help. Gender discrimination is rarely seen in large cities of 
China nowadays. However, in rural areas, this phenomenon is still common. As the students are receiving education from university, and especially learning Western culture through American English, the idea of equality has interiorized into the students' hearts. There is a portion of college students that come from rural areas, where Gender discrimination is still a common phenomenon. However, with the study of English, the idea of equality has spread among them. Female students are aware that they can do as well as the male students do, and they are acting more independently and with the initiative in their own hands.

The idea of equality does not only go for human kind, but also is true to animals. In traditional Chinese culture, the balance between human beings and other animals is not that harmonious. In America, dogs, cats and other animals are treated as very close friends or family members. When taking English courses in college, it is very common for students to get access to American movies that describe the close relationship between animals and mankind. Like the famous movie "Lassie Come Home"tells a story about a Collie travel across England to try to find his master. This movie vividly describes the loyalty of dogs and the moving relationship between dogs and men. Other movies like "Eight Below", "Marley \& Me”, "Bolt”, "Hachiko: A Dog's Story" greatly influenced the young generation's idea towards dogs or other animals. Many college students have pets in their homes; they name their pets with lovely names and treat them as their best friends. In society, with more and more people join in the groups of animal protection and few restaurants are selling the meat of the dog.

In the meantime, the idea of natural selection is still affecting Chinese college students. Competitions are getting fiercer every year. Now, students are becoming more mutual before they actually step into the complex society. They are more diplomatic in ways of dealing with other peoples, they are eager, restless, talkative, ignorant bunch, but casually kind and impersonal for all that are new to them. In English classes, students are often required to stand on the stage in front of other students to give presentations, speeches or oral plays. In this way, students' abilities have been greatly cultivated. They won't be shy when they are having job interviews and they are more likely to show the best side of themselves. Such competitions would benefit both the students and the employers as long as it wouldn't turn into cutthroat competition.

\section{The Side-Effects of American Ideology}

Like a coin, everything has two sides. While the Chinese college students are learning the advanced ideology form American, there are still many dark sides of its ideology. Therefore, it is essential for us to understand the side-effects of American ideology.

Chinese university students are very familiar with festivals like Thanksgiving, Christmas, and Valentine's Day. During these festivals shops are crowded with feverish young people; restaurants' seats are all booked up; TV, radio and advertisements are echoing the songs of festivals. Young university students in China know more about the American festivals than their own country's festivals. As a matter of fact, researches show that now students at college are more willing to celebrate festivals like Thanksgiving, Christmas, Valentine's Day than Chinese traditional festivals like Mid-Autumn Festival, Dragon Boat Festival, Double Ninth Festival, etc. Take Valentine's Day for example, young people prefer to celebrate on February 14th instead of the Double Seventh Festival in the traditional Chinese culture, sweet chocolate wrapped up in delicate colorful papers and red roses that present love seem more attractive in the eyes of the young generation. All the romantic scenes described in American movies and novels have already been rooted deep in Chinese young generation's hearts.

Fast foods in McDonald and KFC are all college students' favorite ones, but in fact, eating those fast foods too often is unhealthy for bodies, such as fried chips and carbonated beverages. Besides fast food, American foods like red wine steaks, borsches, Pan Fried Chicken with Herb and so on are also the students' favorite foods. Many students prefer American style food to traditional Chinese food. As for, the style of clothes, students love to buy clothes of American brands, famous brands like E-Land, Old Navy, Gapkid, Levi’s, Betty, Snoopy ... Luxury brands like Calvin klein, Abercrombie and Fitch, Jake Spade, Brooks Brothers, etc. All these dazzling brands inevitably influence students' culture values; when they are trying to follow the trends of American living style, they are likely to lose their own sense of belongings, in other words, their self-identities. This uncertain feeling of losing the selfidentity would exert a subtle influence on their characters, such as inferiority hedonism and blind worship. That is the part we should be particular cautious about.

As to the entertainment, blockbusters of Hollywood movie studios like Universal Picture Co., Paramount Pictures, 20th Century-Fox Film Corp., Columbia Pictures Corp., Warner Bros., Pop songs of American singers like Blues, Jimmy eat the world, Beyonce, Jennifer, TV series like The Big Bang Theory, White Collar, Mentalist, House, Gossip Girls, and others like novels, magazines, newspapers are becoming an inseparable part of college students' lives. During the process of English learning it is very efficient to practice the skill of listening and the sense of language by watching the movies and following the songs. With the learning of English, students' mother language, so Chinese would regress, and thus they are likely to worship American celebrities. College students are easily influenced by American style heroism, hedonism, individualism ... Among them; individualism is the most pestilent one. Chinese value collectivism as the most important ideology advocates people should put the interests of the state and people above all, advocate protects state and collective interests and sacrifice personal interests, while in American people think the individual freedom and personal interests are everyone's basic rights and no one and no institution or government should interfere with others exercise personal rights.

It's a fact that part of the Chinese college students are contempt to traditional culture, therefore, it's important to understand the reason, thus we can promote the patriotic spirit towards China and advance the fine cultural heritage of the nation while we are absorbing the essence from American culture.

\section{Conclusion}

This thesis analyzes the impact of American ideology upon Chinese college students, on the basis of theory of language attrition. When college students are learning American English, there is a psycholinguistic approach that they are likely to lose the mastery of Chinese. For example when they come across some situations in their lives, the first word jumping out of their minds is more likely to be an English one. This is one phenomenon to demonstrate the influence of language attrition on 
Chinese college students. The result of language attrition would lead to the transfer of Chinese college students' ideology, which includes ideas, culture value, self-identities, etc. The analysis of this study suggests that language attrition can provide a potential theoretical and methodological way of its framework to conduct an integrating analysis of the American ideology's impact on Chinese college students on both sides. This thesis serves as a modest spur to induce other's interest to make more valuable contributions to this research. Thus we can better understand the practical significance of foreign language teaching.

\section{REFERENCES}

Abercrombie, N. et al. (2010). The penguin dictionary of sociology. New York, NY: Penguin.

Eagleton, T. (1991). Ideology: An introduction. London: Verso.
Gao, Y. H. (2007). Chinese college students' English learning social psychology. Beijing: Foreign Language Teaching and Research Press.

Köpke, B., \& Monika S. S. (2007). Language attrition: Theoretical perspectives. Amsterdam/Philadelphia: John Benjamins Publishing Company.

Lambert, R. D., \& Barbara, F. (1982). The loss of language skills. Rowley: Newbury House.

Lin, C. D. (2009). The meaning of thinking highly of the English learning. Chinese West Technique, 8, 102.

Weltens, B., \& De Bot, K. (1986). Language attrition in progress. Dordrecht: Foris Publications.

Yang, L. R. (2009). The Investigation of current foreign language attrition. Beijing: Chinese People's Liberation Army (PLA) Foreign Language Institute.

Zhu, W. L. (2002). International cultural strategy research. Shanghai: Shanghai Foreign Language Education Press. 